\title{
TITLE: An empirical examination of echo chambers in US climate policy networks
}

\author{
Authors: Lorien Jasny ${ }^{1,2}$, Joseph Waggle ${ }^{3}$, Dana R. Fisher ${ }^{3 *}$
}

\author{
Affiliations: \\ ${ }^{1}$ National Socio-Environmental Synthesis Center, 1 Park Place, Suite 300, Annapolis, Maryland, \\ 21401, United States. \\ ${ }^{2} \mathrm{Q}-$ Step Centre, University of Exeter \\ ${ }^{3}$ Department of Sociology, University of Maryland, 2112 Art-Sociology, College Park, MD, \\ 20742, United States. \\ *Corresponding author. Please email drfisher@umd.edu.
}

\section{KEY WORDS:}

Climate Politics_-Echo Chambers - Science Communication-Social Network Analysis 


\section{SUMMARY}

Diverse methods have been applied to understand why science continues to be debated within the climate policy domain. A number of studies have presented the notion of the "echo chamber" to model and explain information flow across an array of social settings, finding disproportionate connections among ideologically similar political communicators. This paper builds on these findings to provide a more formal operationalization of the components of echo chambers. We then empirically test their utility using survey data collected from the community of political elites engaged in the contentious issue of climate politics in the United States. Our survey period coincides with the most active and contentious period in the history of US climate policy, when legislation regulating carbon dioxide emissions had passed through the House of Representatives and was being considered in the Senate. We use Exponential Random Graph (ERG) modeling to demonstrate that both the homogeneity of information (the echo) and multi-path information transmission (the chamber) play significant roles in policy communication. We demonstrate that the intersection of these components creates echo chambers in the climate policy network. These results lead to some important conclusions about climate politics, as well as the relationship between science communication and policymaking at the elite level more generally. 


\section{MAIN}

Environmental politics continue to be highly contentious, and nowhere has this debate become more deeply entrenched than in the issue of climate change. Despite a well-documented scientific consensus on the causes and drivers of global climate change, legislation has yet to be passed in the United States at the federal level to address these issues. As scientists continue to warn decisionmakers about the need to act (1-5), the political debate remains polarized. What's more, this political polarization often manifests among political elites as debates over the veracity and legitimacy of established scientific consensus (6). In January 2015, while debating the Keystone XL oil pipeline in the United States Senate, for example, an amendment was offered to get the "sense of the Senate" about whether humans contribute significantly to climate change (7). The vote was split, 50-49, with 49 Senators refusing to affirm that climate change is anthropogenic.

Numerous studies have aimed to understand why the science of climate change continues to be challenged within policy circles, focusing on the media coverage of the issue (8-10), the role that conservative think tanks have played in creating a counter-movement (11-14), and the ways the issue has been discussed by the US Congress $(6,15-16)$. Within this literature, scholars have invoked the notion of echo chambers to describe how information has become a partisan choice, and how those choices bias toward sources that reinforce beliefs rather than challenge them, regardless of the source's legitimacy (17).

Within the broader literature, echo chambers are described as social network formations that transform the ways in which information is transmitted and interpreted by actors (18-22). Scholars have applied this concept to illustrate the dynamics of issue positions of candidates and political parties (23); the public consumption of media (24-25); the homophily of online 
communication networks (26-28), which focuses on the presence of ties among actors who share the same attribute (29); and multiple aspects of blogs and blog-based discussion (17, 29-33). This paper builds on this extant literature by providing a more formal operationalization of the components of echo chambers and then testing empirically for their presence against competing network mechanisms within the US climate policy network.

We conceive of the echo chamber as being comprised of two distinct processes. First, information is an "echo" when it repeats what one already believes. Called "confirmation bias" in the psychology literature, information is perceived to be more credible when it matches the recipient's worldview (34-35), or when individuals hear the same information from different sources, even if that information ultimately came from one original source (35-36). Additionally, hearing repeated messages has been found to intensify viewpoints further and push some to extreme opinions (37-40). Although this process of influence homophily in information transmission involves some element of time, in this first examination of the echo chamber, we test this operationalization with a static model.

The second mechanism is the formation of "chambers," or structures that provide the space needed for information to echo. Our "chamber" is the smallest network structure that provides the conditions for the same information to be transmitted from one source to one recipient via different paths. In other words, as we describe in detail below, the "chamber" involves at least three actors: a speaker, a receiver, and a mediating actor through which the information can travel. This directed multi-path transmission distinguishes echo chambers from other polarization mechanisms $(16,38-42)$. The combination of homophily with the bonding social capital found in cohesive triads (19) makes these echo chambers a fundamentally different network structure. In the pages that follow, we depart from the previous literature on echo 
chambers by examining the interaction of the echo and chamber mechanisms within a statistical framework.

To accomplish this goal, we examine the information networks that supplied members of the climate policy community in the United States in 2010 with research, advice, and perspectives on climate change. Below, we briefly describe the data collected, operationalize our understanding of echo chambers using social network methods, and apply Exponential Random Graph (hereafter, ERG) model simulation methods to test for the presence and significance (relative to tie formation) of such echo chambers among members of the US climate policy network. For a full discussion of the policy network approach, which uses policy actors at the unit of analysis, see the work of Knoke (41) and Laumann and Knoke (43).

Our network is comprised of the set of the policy actors in our sample who responded to our survey (64 in total) and all reported directed communication within this population. For example, when actor $B$ states that they received information from actor $A$, there is a directed tie from $A$ to $B$ (Fig 1a). Given this network formalism, we can now specify the two characteristics of echo chambers.

\section{Figure 1 about here}

The "echo" is the sharing of information between two actors who have the same outlook or opinion on a relevant issue. This attribute status is represented by the shading of the circles (representing the actors) in Fig 1b (as opposed to the clear circles in 1a). The "chamber" mechanism, in contrast, has information from the same source reaching the same endpoint via multiple different paths. The smallest structural configuration that would depict this process is the transitive triad. In this structure, information passes from actor $A$ to actor $C$ through a direct 
tie, but also indirectly through actor $B$ (such that $B$ receives information from $A$, and $C$ receives information from $B$; see Fig 1c).

To show that an echo chamber exists, we must demonstrate that these chambers are configured around policy actors with the same viewpoint (as depicted in Figure 1d). Figure 2 shows the ego networks of some of the key players in our network, based on their sources of "expert scientific information" and their responses to an attitudinal question that asks them to identify their organization's position from "strongly agree" to "strongly disagree" on the statement: There should be an international binding commitment on all nations to reduce $G H G$ emissions (one of several attributes included in the analysis). The Office of Representative Ed Markey (who sponsored The American Clean Energy and Security Act), and a Columbia University scientist well-known to support the scientific consensus position in the climate debate appear in the top row. The Office of noted climate change denier and newly seated chairman of the Senate Committee on Environment and Public Works, Senator James Inhofe, appears in the bottom row along with a University of Alabama scientist who has spoken extensively against the notion that climate change is anthropogenic.

Figure 2 about here

Although Figure 2 displays the existence of some transitive triads in the network, descriptive measures alone cannot determine whether the number of transitive triads present could be explained by other network properties. For example, some such triads could be formed by chance, simply due to the number of edges present in the network (note that the number of triads increases with the number of alters and ties in the ego network). Similarly, we must determine whether the empirical level of homophily observed - that an actor uses a source with 
the same opinion as him/herself — is also not due to random tie formation. Additionally, in order to establish the presence of an echo chamber, our data must show, not only that both an echo and a chamber are operating, but that the transitive triads within which the information is transmitting are themselves sorted by homophily. In other words, we must show that echo chambers are statistically more likely to occur within like-minded, homophilous groups.

In this study, we analyze network formation based on political actors' agreement with three key statements that have been found to be of central concern to policy actors engaged in recent US climate politics $(6,44)$ : There should be an international binding commitment on all nations to reduce GHG emissions (Binding); Emissions trading (cap and trade) is the best option for reducing US GHG emissions (Cap and Trade), and; Human activities are an important driver of current global climate change (Anthropogenic). For each of these questions, we include a term for the general tendency of higher-scoring actors to be cited as a source (Fig 3f) as well as heterophily terms (Fig 3g), which measures the likelihood of a tie between two actors as a function of the difference in their responses to each attribute question increases. A negative coefficient for this term indicates that two actors with different responses are unlikely to be tied, and thus is interpreted as a tendency towards homophily. These terms represent our "echo" mechanism. Finally, we include the "chamber" term -- transitive triads (Fig 3d) - and a term for the interaction of homophily and transitive triads - the full "echo chamber" (Fig 3h). For the attribute component in each of these terms, agreement was coded as the exact same value in the 5-point response scale.

Figure 3 about here 
Figure 4 presents the results of the ERG model analysis from the best fitting model (see the Supplement for a comparison of 12 models). The coefficients are the log-odds likelihood of a tie fulfilling the given condition. Thus, if adding an edge adds one more to the count of transitive triads in which all actors responded with the same level of agreement to the question There should be an international binding commitment on all nations to reduce GHG emissions, the likelihood of that tie occurring increases significantly by 0.274 in log-odds or a probability of 57\%. This log-odds is added to any other probabilities the given edge also fulfills. The other significant attribute terms in the model are a density term indicating a preference to pick information sources with higher ratings on the Anthropogenic question (Anthropogenic: Sender) and homophily (indicated by negative heterophily - Anthropogenic: Heterophily).

The significant control variables indicate that scientific actors and those from the Executive Branch of the US government were more frequently cited as sources of information (compared to the baseline of business organizations). Although it is encouraging that science is widely cited as a source of information on climate change in our network, it is also important to note that science itself is not a monolithic community. Science networks form in varied and often unpredictable ways around the formation of knowledge, and are susceptible to political, ideological, and cultural pressures (45).

The structural parameters show a clear tendency towards popularity (the positive and significant 2-star coefficient), which indicates that many of the political actors in our sample get their information from the same sources. We also see no tendency for transitive triads in general outside those that count towards the number of transitive triads segregated by their agreement with the Binding variable. For additional verification of model quality and goodness of fit, see the Supplement. 


\section{Figure 4 about here}

Although we might expect high levels of transitivity to be beneficial in some social relationships, like friendship (46-47) and cooperation (48-49), these structures have a very different impact in networks of information transmission. For communication networks, the repeated nature of the ties may give members the impression that an issue is decided when there continues to be debate. In the case of climate change, however, echo chambers may also amplify divergence from the consensus position. In other words, a few dissenting voices can be echoed and amplified so heavily through the chamber that they appear to represent a substantial number of dissenters. Likewise, an echo chamber also has the potential to amplify convergence. Echo chambers themselves are value-free; their impact on political discussion and debate are an effect of context and content. In the context of federal US climate politics, our empirical model of echo chambers provides a potential explanation for why conservative political actors continue to discuss climate change science as undecided when, by all reasonable measures, the scientific community has reached consensus.

Future research must engage this operationalization to investigate how and to what degree these structures work in other information-seeking settings. Using ERG modeling techniques will also permit the disentangling of echo chamber effects from other polarizing structures. Additionally, although there are implications in our analysis for information diffusion over time, our present data only allow for tests of echo chambers in one static network. Expansions on this work should engage with temporal data to explore the nascence and formation of echo chambers (asking, for example, which comes first: the echo or the chamber?) drawing on current research into influence versus selection mechanisms in homophily (50). The 
present analysis also provides a foundation for future work that compares echo chambers across actor networks engaged in other policy arenas.

Finally, studying echo chambers can shed light on the complex relationship between political actors and the scientific expertise they engage. Our findings suggest that scientific experts are called upon by political actors, not just for the completeness of their knowledge, but for how well they fit into particular political narratives. The opinions measured in this article do not deal with scientific fact; rather, they measure policy debates that surround climate change, an issue that has been framed as wholly scientific in nature. Social structures that increase partisanship and extremity in these views do little else but hamper political and scientific progress (51). We expect these findings to be consistent with other samples of elite political actors engaged in decision-making processes. Further study of echo chambers will contribute to scientific communication above the amplified noise inside these chambers. 


\section{REFERENCES}

1. Jorgenson, A.K. Energy: Analyzing fossil-fuel displacement Nature Clim. Change 2, 398-399 (2012).

2. Jorgenson, A.K. Economic development and the carbon intensity of human well-being. Nature Clim. Change 4, 186-189 (2014).

3. Rogelj, J., McCollum, D.L., Reisinger, A., Meinschausen, M., Riahi, K. Probabilistic cost estimates for climate change mitigation. Nature 493, 79-83 (2013).

4. Loarie, S.R. et al. The velocity of climate change. Nature 462, 1052-1055 (2009).

5. Meinhausen, M. et al. Greenhouse-gas emission targets for limiting global warming to 2C. Nature 458, 1158-1162 (2009).

6. Fisher D.R., Waggle, J., Liefeld, P. Where does political polarization come from? Locating polarization within the U.S. climate change debate. Am. Behav. Sci. 57, 70-92 (2013).

7. Biello, D. Senators vote in circles about global warming and the Keystone XL Pipeline. Sci. Am. Online (2015).

Available online at: http://blogs.scientificamerican.com/observations/2015/01/30/senatorsvote-in-circles-about-global-warming-and-the-keystone-xl-pipeline/

8. McComas, K., Shanahan, J. Telling stories about global climate change: Measuring the impact of narratives on issue cycles. Comm. Res. 26, 30-57 (1999).

9. Shanahan, J., Good, J. Heat and hot air: influence of local temperatures on journalists' coverage of global warming. Pub. Under. Sci. 9, 285-295 (2000).

10. Weingart, P., Engels, A., Pansegrau, P. Risks of communication: discourses on climate change in science, politics, and the mass media. Pub. Under. Sci. 9, 261-283 (2000). 11. Jacques, P.J., Dunlap, R.E., Freeman, M. The organisation of denial: Conservative think tanks and environmental scepticism. Enviro. Pol. 17, 349-385 (2008).

12. Meyer, D.S., Staggenborg, S. Movements, countermovements, and the structure of political opportunity. Am. J. of Soc. 101, 1628-1660 (1996).

13. Liu, X., Lindquist, E., Vedlitz, A. Explaining media and Congressional attention to global climate change, 1969-2005: An empirical test of agenda-setting theory. Pol Res $Q$ 64, 1-15 (2009).

14. McCright, A.M., Dunlap, R.E. Challenging global warming as a social problem: An analysis of the conservative movement's counter-claims. Soc. Prob. 47, 499-522 (2000). 15. Feldman, L., Myers, T., Hmielowski, J., Leiserowitz, A. The mutual reinforcement of media selectivity effects: Testing the reinforcing spirals framework in the context of global warming. J. Comm. 64, 590-611 (2014).

16. Dandekar, P., Goel, A., Lee, D.T. Biased assimilation, homophily and the dynamics of polarization. Proc. Natl. Acad. Sci. 110, 5791-696 (2013).

17. Adamic, L., Glance, N. The political blogosphere and the 2004 U.S. election: Divided they blog. Proc. Intl. Wkshp. on Link. Disc. $3^{\text {rd }}$ ed. (LinkKDD-2005; Chicago, IL 2005).

18. Uzzi, B., Dunlap, S. How to build your network. Harvard Bus. Rev. 83, 53-60 (2005).

19. Burt, R.S. in Networks and Markets. Rauch, J.E., Casella, A., eds. (Russell Sage

Foundation, 2001).

20. Key, Jr., V.O. The Responsible Electorate (Harvard University Press, 1966).

21. Callison, C. Distorting the climate message. Nature 463, 161-162 (2010). 
22. Alvarez, R.M., Nagler, J. Party system compactness: Measurement and consequences. Pol. An. 12, 46-62 (2004).

23. Garrett, R.K. Echo chambers online? Politically motivated selective exposure among internet news users. J. of Com-Med. Comm. 14, 265-285 (2009).

24. Jamieson, K.H., Cappella, J.N. Echo Chamber: Rush Limbaugh and the Conservative Media Establishment (Oxford University Press, 2008).

25. Peters, H.P. Gap between science and media revisited: Scientists as public communicators. Proc. Natl. Acad. Sci. 110, 14102-14109 (2013).

26. Boutyline, A., Willer, R. The Social structure of political echo chambers: Ideology and political homophily in online communication networks. White paper. (2014).

Available online at: https://www.ocf.berkeley.edu/ andrei/downloads/echo.pdf

27. Gleeson, J.P. et al. A simple generative model of collective online behavior. Proc. Natl. Acad. Sci. 111, 10411-10415 (2014).

28. Lewis, K., Gonzalez, M., Kaufman, J. Social selection and peer influence in an online social network. Proc. Natl. Acad. Sci. 109, 68-72 (2012).

29. McPherson, M., Smith-Lovin, L., Cook, J.M. Birds of a feather: Homophily in social networks. Annu. Rev. Sociol. 27, 415-444 (2001).

30. Wallsten, K. Political blogs and the bloggers who blog them: Is the political blogosphere an echo chamber? Presented at American Political Science Association Annual Meeting. (2005)

31. Gilbert, E., Bergstrom, T., Karahalios, K. Blogs are echo chambers Proc. HICSS (2009). 32. Onnela, J.P., Reed-Tsochas, F. Spontaneous emergence of social influence in online systems. Proc. Natl. Acad. Sci. 107, 18375-18380 (2010).

33. Reese, S.D., Rutigliano, L., Hyun, K., Jeong, J. Mapping the blogosphere: Professional and citizen-based media in the global news arena. Journalism 8, 235-261 (2007).

34. Nickerson, R.S. Confirmation bias: A ubiquitous phenomenon in many guises. Rev. Gen. Psych. 2, 175-220 (1998).

35. Butts, C.T. A Bayesian model of panic in belief. CMOT 4, 373-404 (1998).

36. Weaver, K., Garcia, S.M., Schwarz, N., Miller, D.T. Inferring the popularity of an opinion from its familiarity: A repetitive voice can sound like a chorus. J. of Pers. and Soc. Psych. 92, 821-833 (2007).

37. Mas, M., Flache, A. Differentiation without distancing: Explaining bi-polarization of opinions without negative influence. PLoS ONE 8, e 74516 (2013).

38. Stroud, N.J. Niche News: The Politics of News Choice. (Cambridge University Press, 2011).

39. Jamieson, K.H., Hardy, B.W. Leveraging scientific credibility about Arctic sea ice trends in a polarized political environment. Proc. Natl. Acad. Sci. 111, 13598-13605 (2014).

40. Macy, M.W., Kitts, J.A., Flache, A., Benard, S. Polarization in dynamic networks: A Hopfield model of emergent structures. 162-173 in Dynamic Social Network Modeling and Analysis: Workshop Summary and Papers, Breiger, R., Carley, K., Pattison, P., eds. (National Academies Press, 2003).

41. Knoke, D. Political Networks: The Structural Perspective (Cambridge University Press, 1990).

42. Roodhouse, E.A. The voice from the base(ment): Stridency, referential structure, and partisan conformity in the political blogosphere. First Monday 14, 9 (2009). 
43. Laumann, E.O., Knoke, D. The Organizational State: Social Choice in National Policy Domains (University of Wisconsin Press, 1987).

44. Fisher, D.R., Leifeld, P., Iwaki, Y. Mapping the ideological networks of American climate politics. Clim. Change 116, 523-545 (2013).

45. Shwed, U., Bearman, P.S. The temporal structure of scientific consensus formation. Am. Soc. Rev. 75, 817-840 (2010).

46. Christakis, N.A., Fowler, J.H. Friendship and natural selection. Proc. Natl. Acad. Sci. 111, 10796-10801 (2014).

47. Eagle, N., Pentland, A.S., Lazer, D. Inferring friendship network structure by using mobile phone data. Proc. Natl. Acad. Sci. 109, 15274-15278 (2009).

48. Fowler, J.H., Christakis, N.A. Cooperative behavior cascades in human social networks. Proc. Natl. Acad. Sci. 107, 5334-5338 (2010).

49. Rand, D.G., Arbesman, S., and Christakis, N.A. Dynamic social networks promote cooperation in experiments with humans. Proc. Natl. Acad. Sci. 108, 19193-19198 (2011). 50. Lazer, D., Rubineau, B., Chetkovich, C., Katz, N., Neblo, M. The coevolution of networks and political attitudes. Pol. Comm. 27, 248-274 (2010).

51. Scheufele, D. Science communication as political communication. Proc. Natl. Acad. Sci. 111, 13585-13592 (2014). 


\section{SUPPLEMENTARY INFORMATION}

Supplementary information is available in the online version of this paper.

\section{CORRESPONDENCE:}

All correspondence for this project should be directed to:

Dana R. Fisher

Professor of Sociology

2112 Art-Sociology, University of Maryland

College Park, MD 20742

drfisher@umd.edu

\section{ACKNOWLEDGEMENTS:}

This research was supported by the U.S. National Science Foundation (BCS-0826892) and the National Socio-Environmental Synthesis Center (SESYNC) (DBI-1052875). The authors would like to thank Katherine Krimmel and Maria Abascal for their help in collecting some of the data used in this paper. The authors would also like to thank Philip Leifeld, Margaret Palmer, and Philip Cohen for providing comments on earlier drafts of this paper.

\section{AUTHOR CONTRIBUTIONS:}

DRF directed data collection. $\mathrm{LJ}$ was responsible for data analysis. JW cleaned data and prepared reports and drafts of the manuscript. All authors contributed to project design, write-up of findings, and revisions.

\section{ADDITIONAL INFORMATION:}


Reprints and permissions information is available at www.nature.com/reprints. The authors declare no competing financial interests. Readers are invited to comment on the online version of the paper. 